\title{
Carotid Intima and Media Thickness Correlation with Central Blood Pressure Measurements by Tonometric and Oscillometric Methods: A Proof of Concept
}

Weimar Kunz Sebba Barroso, ${ }^{1 \oplus}$ Milena de Andrade Melo, ${ }^{1 \oplus}$ Priscila Valverde Vitorino, ${ }^{2}{ }^{\oplus}$ Claudia Gonçalves, ${ }^{1 \oplus}$ João Alexandre Berigó, ${ }^{\circledR}$ Ana Carolina Arantes, ${ }^{\circledR}$ Jeeziane Rezende, ${ }^{1}$ Thiago Veiga Jardim, ${ }^{1 \oplus}$ Ana Luiza Lima Souza, ${ }^{1 \oplus}$ Paulo César Veiga Jardim ${ }^{10}$

Liga De Hipertensão Arterial - Universidade Federal de Goiás,' Goiânia, GO - Brazil

Pontifícia Universidade Católica de Goiás, ${ }^{2}$ Goiânia, GO - Brazil

\section{Abstract}

Background: The early detection of vascular damage in subclinical stages of hypertensive disease may be the key point in the prevention of cardiovascular outcomes.

Objectives: to correlate parameters of structural vascular damage (measurement of the carotid intima-media thickness) with parameters of functional vascular damage (central hemodynamic measurements) in pre-hypertensive and hypertensive patients taking up to two classes of anti-hypertensive drugs.

Methods: This was a cross-sectional descriptive study conducted with a convenience sample of patients attending the Liga de Hipertensão Arterial, a multidisciplinary program for the diagnosis and treatment of systemic hypertension, of the Federal university of Goias. Patients with arrythmia, diabetes, previous cardiovascular or cerebrovascular diseases, and end-stage diseases were excluded. Carotid Doppler test, measurements of peripheral and central blood pressure by applanation tonometry (Sphygmocor $\left.{ }^{\circledR}\right)$ and oscillometry (Mobil-O-Graph ${ }^{\circledR}$ ) were performed. The t-test was used for comparisons and the Pearson correlation test for correlations, considering a $\mathrm{p}<0.05$ statistically significant.

Results: twenty patients (12 women) were evaluated, mean age $53.8 \pm 14.3$ years. Higher values of central pulse pressure $(42.9 \pm 13.9$ vs. $34.7 \pm 9.6, \mathrm{p}=0.01)$ and pulse wave velocity (PWV) $(9.0 \pm 1.9$ vs. $7.9 \pm 1.5, \mathrm{p}=0.01)$ were obtained by applanation tonometry compared with oscillometry. No difference between the methods was observed for the other measures. A significant correlation was found between carotid artery intima-media thickness (CA-IMT) and PWV ( $r=0.659 ; \mathrm{p}=0.002)$ by the oscillometric test, but not with applanation tonometry. No correlation was found between central hemodynamic variables and the presence of carotid artery plaques.

Conclusion: PWV, estimated by oscillometry, was the only central hemodynamic parameter that correlated significantly with CA-IMT in pre-hypertensive and hypertensive patients at low cardiovascular risk. (Int J Cardiovasc Sci. 2021; 34(1):22-29)

Keywords: Cardiovascular Diseases/prevention and control; Carotid Intima - Media Thickness; Blood Pressure; Vascular Stiffness; Hypertension; Manometry/ methods; Oscillometry/methods.

\section{Introduction}

The early detection of vascular injury in subclinical hypertensive disease may be the key point to delay or even prevent major cardiovascular outcomes. ${ }^{1}$

The measurement of the carotid artery intima-media thickness (CA-IMT) using ultrasound is a low cost, available, reproducible method, with no risks associated, and with good histopathological correlation. ${ }^{2}$ It is useful as a non-invasive assessment method of vascular hypertrophy and atherosclerotic disease, ${ }^{3}$ it is considered a robust predictor of cardiovascular events and surrogate marker of atherosclerosis. Its clinical use is a component of the risk score for coronary events. ${ }^{4}$ 
However, functional vascular damage can also be assessed by central hemodynamic and arterial stiffness parameters. ${ }^{5}$ The knowledge of the concepts of pulse wave velocity (PWV), central blood pressure (cBP), central pulse pressure (cPP) and augmentation index (AIx) promotes a broader and clearer view of lesions in the target organ, and its prevention and treatment. ${ }^{6}$

Many non-invasive devices aiming to estimate these parameters have been developed, tested and validated. The analysis is made from pulse waves obtained from arterial beds far from the aorta. ${ }^{7}$ In these transfer models, principles and methods of calibration or substitution of different signals (applanation tonometry, oscillometry, ultrasound and magnetic resonance imaging) are used, each with advantages and limitations. The oscillometric method tends to underestimate PWV compared with tonometry and intra-arterial measurements. ${ }^{8}$

SphygmoCor $®$ is an instrument that provides measurement of PWV in the femoral and carotid arteries by applanation tonometry. The system, validated and used for decades, is currently considered the gold standard non-invasive method for acquisition of central hemodynamic measures. ${ }^{8}$

The oscillometric method, here represented by the Mobil-O-Graph ${ }^{\circledR}$ monitor, measures peripheral artery (usually brachial or radial artery) PWV and reconstructs the central pulse wave by applying a transfer function. ${ }^{9}$ This is a technically simple method, with a good cost-benefit relationship compared with tonometry. ${ }^{10}$

We performed a proof-of-concept study, aiming to demonstrate that, despite underestimating PWV, the oscillometric method provides the best correlation with structural damage of the artery compared with tonometry in pre-hypertensive patients and low-risk hypertensive patients. To achieve this, we correlated structural vascular abnormalities (CA-IMT) with functional (central hemodynamic) parameters obtained by tonometry (Sphygmocor $^{\circledR}$ ) and oscillometry (Mobil-O-graph ${ }^{\circledR}$ ).

\section{Methods}

This was a descriptive cross-sectional study conducted with patients enrolled in the Liga de Hipertensão Arterial (LHA), a multidisciplinary program for the diagnosis and treatment of systemic hypertension, of the Federal University of Goias, Brazil. The study was approved by the ethics committee of the university General Hospital (approval number 000985/2016).
The sample was selected between March and July 2016 from 1,500 patients enrolled in the LHA, by review of active medical records and completion of a specific form, previously developed for the study. Two hundred and forty patients were considered eligible. Inclusion criteria were patients older than 18 years, pre-hypertensive or stage 1 hypertensive patients taking up to two different antihypertensive classes. Exclusion criteria were patients enrolled in other research protocols within less than one year and patients with comorbidities potentially predisposing to endothelial dysfunction, such as diabetes, ${ }^{11}$ end-stage chronic diseases, including chronic renal failure and congestive heart failure, ${ }^{12}$ and previous cardiovascular and cerebrovascular diseases, such as coronary artery disease and ischemic stroke.

In the second phase of the study, telephone contact was attempted for the eligible patients; after three unsuccessful attempts in different days and times the patients were excluded. When successfully contacted, the patient was invited to attend the LHA in two days - the first for blood pressure measurements and the second (scheduled day and time) for carotid Doppler study.

Thirty-six patients were included. After the interview and imaging tests, two patients were excluded due to history of ischemic stroke, two for arrhythmia, which would affect cBP measurements, and 12 quit participating. Therefore, the convenience sample was composed of 20 participants.

On the first day of the study, each patient was seen in a private room and instructed about the study, and those willing to participate signed an informed consent form. Subsequently, the patients completed a questionnaire on anthropometric data, lifestyle, previous diseases, and underwent central and peripheral blood pressure measurements and carotid Doppler ultrasound.

Peripheral blood pressure was measured at the office according to standard procedures recommended by the Brazilian guidelines on blood pressure. ${ }^{12} \mathrm{~A}$ semiautomated device (OMRON®, model HEM-705CP) was used, which was validated by international centers and has been recommended for epidemiological studies. ${ }^{13}$

Measurement of cBP was made using two different methods - applanation tonometry, performed using a SphygmoCor ${ }^{\circledR}$ device, which was calibrated, and clinically validated by the European Society of Hypertension (ESH) and the European Society Cardiology (ESC). ${ }^{14}$ The instrument consists of a 
tonometer (portable pressure transducer or sensor) coupled to a computer with dedicated software for collection and analysis of the data. Patients' personal and anthropometric data, medications used, and peripheral blood pressure ( $\mathrm{pBP}$ ) assessed during the first visit were inserted to the system. When used on the radial artery, SphygmoCor ${ }^{\circledR}$ also obtains measures related to central systolic (cSBP) and diastolic blood pressure (cDBP), pulse pressure amplification (PPA), cPP and AIx by transfer function. When used on carotid and femoral arteries, the system also calculates the carotid-femoral PWV. ${ }^{14}$

The oscillometric method was performed using the Mobil-O-Graph ${ }^{\circledR}$, a validated device that estimates cBP from pulse wave acquired from the brachial artery using a pressure cuff. ${ }^{8}$ Data are analyzed by a dedicated software. ${ }^{8}$ Similar to the SphygmoCor ${ }^{\circledR}$, the Mobil $\mathrm{O}^{\prime} \mathrm{Graph}$ also allows the determination of cBP, PWV, AIx, CPP and PPA, and parameters related to arterial resistance and compliance. Central BP measurements were made with patients in siting position, as previously established.

On a second day, carotid Doppler test was performed to assess early structural vascular changes based on the IMT. The test was performed at the Division of Echocardiography of Federal University of Goias General Hospital the using the Toshiba Xario ultrasound system, with a wideband, linear array transducer, central frequency of $7.5 \mathrm{MHz}(5.0-11.0 \mathrm{MHz})$ in a longitudinal section - two-dimensional B-mode imaging. ${ }^{4}$ The test was performed with patient in supine position, head at $45^{\circ}$ in the opposite direction to the side examined.

CA-IMT measures were obtained from distal right and left common carotid arteries, $1 \mathrm{~cm}$ from the carotid artery bifurcation, considering the distance between the two echogenic lines represented by the lumen-intima and the media-adventitia interfaces of the arterial wall, following the American Society of Echocardiography $(2008)^{15}$ and the European Society of Echocardiography ${ }^{14}$ consensus.

\section{Statistical analysis}

First, a descriptive statistical analysis was carried out, using absolute and relative frequencies for qualitative variables and mean, standard deviation (SD) and 95\% confidence interval for quantitative variables.

The t-test was used for comparisons of central pressure measures between the methods (SphygmoCor ${ }^{\circledR}$ and Mobil-O-Graph ${ }^{\circledR}$ ) and of arterial stiffness indices between patients with and without plaques in the carotid arteries.
The Pearson correlation test was used for correlations of CA-IMT measures with pBP, cBP and central hemodynamics. For analysis of CA-IMT, the highest value obtained from the carotid arteries as well as the mean of the measures were used for analysis.

A data analysis and statistical software, Stata, version 14.0, was used for the statistical analyses. A $p<0.05$ was set as statistically significant.

\section{Results}

Twenty individuals (12 women, 60\%), mean age of $53.8 \pm 14.3$ years participated in the study. Mean body mass index was $28.4 \pm 5.2 \mathrm{Kg} / \mathrm{m}^{2}$. Five (25\%) patients did not take any medication, eight (40\%) took only one class of anti-hypertensive drugs; angiotensin receptor blockers were the most used. Most patients had a sedentary lifestyle, did not consume alcohol, and did not smoke (Table 1).

Central hemodynamic measures obtained by the SphygmoCor ${ }^{\circledR}$ and the Mobil-O-Graph ${ }^{\circledR}$ were not different, except for $\mathrm{cPP}$ and PWV, which were lower

Table 1 - Characteristics of the study sample regarding use of anti-hypertensive drugs and lifestyle $(n=15)$

\begin{tabular}{lcc}
\hline Variable & $\mathbf{n}$ & $\%$ \\
\hline Class of drugs & 11 & 73.3 \\
Angiotensin receptor blocker & 02 & 13.3 \\
Angiotensin converter enzyme inhibitor & 06 & 40.0 \\
Diuretics & 02 & 13.3 \\
Beta-blockers & 01 & 6.6 \\
Calcium channel blockers & & \\
Physically active & 06 & 30.0 \\
Yes & 14 & 70.0 \\
No & & \\
Alcohol consumption & & \\
No & 10 & 50.0 \\
Yes & 08 & 40.0 \\
Ex-consumer & 02 & 10.0 \\
Smoker & & \\
No & 15 & 75.0 \\
Yes & 03 & 15.0 \\
\hline
\end{tabular}


using the Mobil-O-Graph ${ }^{\circledR}$ than the SphygmoCor ${ }^{\circledR}$ (Table 2).

No correlation was found between CA-IMT and pBP or cBP. CA-IMT correlated with PWV values obtained by the oscillometric method (Mobil-O-
Graph $^{\circledast}$ ) (Table 3). Mean CA-IMT also correlated with PWV (Table 4).

Arterial stiffness parameters (AIx and PWV) were not different between patients with and without carotid artery plaque (Table 5).

Table 2 - Central blood pressure measures estimated by SphygmoCor ${ }^{\circledR}$ and Mobil-O-Graph ${ }^{\circledR}(\mathrm{n}=20)$

\begin{tabular}{|c|c|c|c|c|c|}
\hline \multirow{2}{*}{ Variable } & \multicolumn{2}{|c|}{ Sphygmocor } & \multicolumn{2}{|c|}{ Mobil-O-Graph } & \multirow[t]{2}{*}{$\mathrm{p}$} \\
\hline & Mean $\pm S D$ & $95 \% \mathrm{CI}$ & Mean $\pm S D$ & IC95\% & \\
\hline cSBP & $123.6 \pm 23.1$ & $112.8-134.4$ & $116.8 \pm 25.1$ & 105.1-128.6 & 0.05 \\
\hline cDBP & $80.0 \pm 15.6$ & $73.5-88.1$ & $81.4 \pm 14.6$ & $74.6-88.2$ & 0.79 \\
\hline cPP & $42.9 \pm 13.9$ & $36.4-49.4$ & $34.7 \pm 9.6$ & $30.1-39.1$ & 0.01 \\
\hline PPA & $12.2 \pm 8.8$ & $8.1-16.3$ & $11.3 \pm 4.1$ & $9.4-13.2$ & 0.63 \\
\hline AIx & $22.4 \pm 11.0$ & $17.3-27.6$ & $22.4 \pm 11.0$ & $17.3-27.5$ & 0.98 \\
\hline PWV & $9.0 \pm 1.9$ & $8.1-9.9$ & $7.9 \pm 1.5$ & $7.1-8.6$ & 0.01 \\
\hline
\end{tabular}

Table 3 - Correlation between carotid intima-media thickness (the greatest measure) and peripheral and central blood pressure obtained by Sphygmocor ${ }^{\circledR}$ and Mobil-O-graph ${ }^{\circledR}$

\begin{tabular}{|c|c|c|c|}
\hline Variables & Device & $\mathbf{r}$ & p \\
\hline \multicolumn{4}{|l|}{ Peripheral measures } \\
\hline Peripheral systolic pressure & OMRON® & 0.298 & 0.201 \\
\hline Peripheral diastolic pressure & OMRON® & 0.190 & 0.420 \\
\hline \multicolumn{4}{|l|}{ Central measures } \\
\hline \multirow[t]{2}{*}{ Central systolic pressure } & Sphygmocor ${ }^{\circledR}$ & 0.317 & 0.172 \\
\hline & Mobil-O-graph® & 0.215 & 0.361 \\
\hline \multirow[t]{2}{*}{ Central diastolic pressure } & Sphygmocor ${ }^{\circledR}$ & 0.280 & 0.231 \\
\hline & Mobil-O-graph® & 0.100 & 0.679 \\
\hline \multirow[t]{2}{*}{ Central pulse pressure } & Sphygmocor ${ }^{\circledR}$ & 0.288 & 0.217 \\
\hline & Mobil-O-graph® & 0.440 & 0.052 \\
\hline \multirow[t]{2}{*}{ Pulse pressure amplification } & Sphygmocor ${ }^{\circledR}$ & 0.006 & 0.809 \\
\hline & Mobil-O-graph® & -0.007 & 0.751 \\
\hline \multirow[t]{2}{*}{ Augmentation index } & Sphygmocor ${ }^{\circledR}$ & 0.111 & 0.640 \\
\hline & Mobil-O-graph® & 0.185 & 0.434 \\
\hline \multirow[t]{2}{*}{ Pulse wave velocity } & Sphygmocor ${ }^{\circledR}$ & 0.266 & 0.255 \\
\hline & Mobil-O-graph® & 0.659 & 0.002 \\
\hline
\end{tabular}


Table 4 - Correlation between mean carotid intima-media thickness and peripheral and central blood pressure measures obtained by Sphygmocor ${ }^{\circledR}$ and Mobil-O-graph ${ }^{\circledR}$

\begin{tabular}{|c|c|c|c|}
\hline Variables & Device & $\mathbf{r}$ & $\mathrm{p}$ \\
\hline \multicolumn{4}{|l|}{ Peripheral measures } \\
\hline Peripheral systolic pressure & OMRON® & 0.29 & 0.217 \\
\hline Peripheral diastolic pressure & OMRON® & 0.216 & 0.361 \\
\hline \multicolumn{4}{|l|}{ Central measures } \\
\hline \multirow[t]{2}{*}{ Central systolic pressure } & Sphygmocor ${ }^{\circledR}$ & 0.334 & 0.151 \\
\hline & Mobil-O-graph ${ }^{\circledR}$ & 0.291 & 0.213 \\
\hline \multirow[t]{2}{*}{ Central diastolic pressure } & Sphygmocor ${ }^{\circledR}$ & 0.242 & 0.305 \\
\hline & Mobil-O-graph ${ }^{\circledR}$ & 0.120 & 0.614 \\
\hline \multirow[t]{2}{*}{ Central pulse pressure } & Sphygmocor ${ }^{\circledR}$ & 0.287 & 0.219 \\
\hline & Mobil-O-graph ${ }^{\circledR}$ & 0.437 & 0.054 \\
\hline \multirow[t]{2}{*}{ Pulse pressure amplification } & Sphygmocor® & 0.020 & 0.932 \\
\hline & Mobil-O-graph ${ }^{\circledR}$ & -0.05 & 0.805 \\
\hline \multirow[t]{2}{*}{ Augmentation index } & Sphygmocor ${ }^{\circledR}$ & 0.148 & 0.533 \\
\hline & Mobil-O-graph ${ }^{\circledR}$ & 0.236 & 0.317 \\
\hline \multirow[t]{2}{*}{ Pulse wave velocity } & Sphygmocor ${ }^{\circledR}$ & 0.271 & 0.247 \\
\hline & Mobil-O-graph ${ }^{\circledR}$ & 0.579 & 0.008 \\
\hline
\end{tabular}

Table 5 - Correlation between presence of carotid artery plaques and arterial stiffness indices obtained by Sphygmocor ${ }^{\circledR}$ and Mobil-O-graph ${ }^{\circledR}$

\begin{tabular}{lccc}
\hline Variable & Absence of plaque (n=14) & Presence of plaque (n=06) & p \\
\hline AIx (Sphygmocor) & $21.8 \pm 11.4$ & $23.8 \pm 10.9$ & 0.724 \\
AIx (Mobil-O-Graph) & $23.1 \pm 10.7$ & $20.8 \pm 5.0$ & 0.687 \\
PWV (Sphygmocor) & $8.8 \pm 2.0$ & $9.6 \pm 1.8$ & 0.422 \\
PWV (Mobil-O-Graph) & $7.4 \pm 1.5$ & $8.8 \pm 1.3$ & 0.078 \\
\hline AIx: Augmentation index; PWV: pulse wave velocity & & \\
\hline
\end{tabular}

\section{Discussion}

The detection of vascular damage at subclinical stages has potential additional value in cardiovascular risk stratification. In the last years, new vascular parameters evaluating both structural and functional properties of the arteries have been introduced as surrogates for outcomes in clinical trials. ${ }^{15}$

Elevated CA-IMT is a morphological indicator of vascular damage. Functional changes usually precede structural changes and can be detected by arterial stiffness detected by hemodynamic indices like PWV.16

Both CA-IMT and PWV have a linear and progressive odds ratio for major cardiovascular outcomes, even in case of slight increases. ${ }^{17}$ The increase in CA-IMT was associated with progression of coronary lesions evaluated by coronary angiography and carotid ultrasound in 558 individuals. When mean IMT was over $1.15 \mathrm{~mm}$, patients had a $94 \%$ probability of having coronary artery disease. ${ }^{18}$ 
In addition, there is evidence indicating that CA-IMT and PWV are associated with the severity of coronary lesions in angiographic analysis of 100 patients. ${ }^{1}$ A longitudinal study with 274 elderly patients followed by eight years showed the importance of these two parameters as indicators of future cardiovascular events, especially when concomitantly used. ${ }^{19}$

In this context, both CA-IMT and PVW are considered important markers of cardiovascular risk by the most important guidelines on arterial hypertension, especially in the initial stages of hypertension and in hypertensive patients at low- or intermediate risk. ${ }^{14}$

In the present study, the correlation between CA-IMT and arterial stiffness was determined $(r=0.659, p=0.002)$ with PWV estimated by oscillometry (Mobil-O-graph ${ }^{\circledR}$ ), but not with PWV estimated by SphygmoCor®.

Most of the few studies available correlating IMT with PWV have used applanation tonometry as it is considered the gold-standard method, and a few studies using plethysmography. ${ }^{20-23}$

A clinical trial with 271 type 2 diabetic patients and 285 healthy controls showed a statistically significant correlation $(\mathrm{p}<0.001)$ between CA-IMT and aortic PWV, obtained by tonometry, in both groups. ${ }^{20}$

A study with hypertensive adolescents reported a significant correlation $(\mathrm{p}<0.05)$ between IMT and brachial-ankle PWV. ${ }^{21}$ Similarly, a study with 135 individuals showed an independent correlation between IMT and brachial-ankle PWV $(\mathrm{p}<0.0001)$ in adults younger than 70 years. ${ }^{22}$ However, one limitation of both studies is the method, since although plethysmography is an easy-to-use, automated method, the PWV values estimated by the method are still questionable as compared with tonometry. ${ }^{23}$

In our study, no difference was found between tonometry and oscillometry for most of the variables studied (Table 3). The lower standard deviation of the values obtained by oscillometry suggests a higher reproducibility of the method compared with tonometry. Lower (or underestimated) values of arterial stiffness measures (cPP and PWV) were found for oscillometry compared with tonometry.

Therefore, one hypothesis for the correlation found between CA-IMT and PWV by the Mobil-O-graph ${ }^{\circledR}$ is the increased specificity resultant from the underestimation of PWV by the oscillometric method.

A study with 254 untreated hypertensive patients compared three non-invasive methods for assessment of cBP - the oscillometric, the piezoelectronic and the tonometric techniques - and showed low reproducibility between the values obtained by the different methods. ${ }^{24}$ Another study, however, conducted with 89 patients, showed high similarity (with high reproducibility and reliability) in PWV obtained by the oscillometric (Tel-O-graph) and the tonometric (SphygmoCor ${ }^{\circledR}$ ) method, which has not been reported by studies using the Mobil-O-graph ${ }^{\circledast 2} .^{25}$

Another study with 564 subjects established an association of IMT and carotid plaques with PVW obtained by tonometry, with an independent association for the presence of carotid plaques. ${ }^{26}$ In contrast, in our study, the presence of carotid plaques did not show correlation with PVW, regardless of the method.

The pathophysiology of atherosclerotic plaque development is different from the IMT progression. In carotid plaque, intimal thickening occurs predominantly with foam cells, smooth muscle cells, macrophages, lipid core, and fibrous cap depending on the stage of plaque development. ${ }^{27}$

A study with 561 individuals without established coronary artery disease evaluated the correlation of arterial stiffness with carotid plaque echogenicity. Mean PWV was not different between patients without carotid plaques and patients with carotid plaques showing low echogenicity. Increased echogenicity was considered a determinant of the association between the presence of carotid plaque and aortic PWV. ${ }^{28}$

Some echocardiographic parameters related to the plaque help in the determination of cardiovascular risk. The degree of stenosis, surface irregularity, echogenicity and texture, which are components of the total plaque risk score, were predictors of ischemic events in the San Daniele study, a general population-based study of 1,348 subjects followed for 12 years. The addition of the plaque characteristics significantly increased the area under the ROC curve compared with the Framingham score alone, indicating that the total plaque risk score is a potential tool for predicting ischemic events. ${ }^{29}$

Therefore, the low association between arterial stiffness indices and the presence of carotid plaques in our study may be explained by morphology and/ or severity of the lesions. Most of the plaques detected were small $(\leq 30 \%)$, with low degree of calcification, corresponding to intermediate echogenicity. Plaque of approximately $45 \%$ was identified in only one patient, with significantly increased PWV values, obtained by both Sphygmocor ${ }^{\circledR}$ and the Mobil-O-graph ${ }^{\circledR}$. 
One limitation of the study was the small sample size. However, the correlation established between structural and functional parameters of vascular damage is important and may serve as a basis for further studies focusing an earlier detection of vascular lesions with potential cardiovascular risk.

\section{Conclusion}

The correlation between IMT and central hemodynamic measures was established in pre-hypertensive and low-risk hypertensive patients. This was true only when PWV calculated by oscillometry $\left(\right.$ Mobil O'graph ${ }^{\circledR}$ ) was considered, and this method is still little explored in this regard.

We did not find any correlation between the presence of carotid plaque and PWV, regardless of the assessment method.

Most of cBP parameters were not different between the two methods, except for $\mathrm{CPP}$ and PWV, which were underestimated by oscillometry.

\section{Author contributions}

Conception and design of the research: Melo MA, Vitorino P, Arantes AC, Sousa ALL, Jardim PC, Jardim T, Souza WKSS. Acquisition of data: Melo MA, Gonçalves C, Berigó JA, Arantes AC. Analysis

\section{References}

1. Zuo G, Zhang M, Jia X, Zheng L, Li Y, Zhao H, et al. Correlation between brachial-ankle pulse wave velocity, carotid artery intima-media thickness, ankle-brachial index, and the severity of coronary lesions. Cell Biochem Biophys. 2014;70(2):1205-11.

2. Skilton MR, Serusclat A, Sethu AH, Brun S, Bernard S, Balkau B, et al. Noninvasive measurement of carotid extra-media thickness: associations with cardiovascular risk factors and intima-media thickness. JACC Cardiovasc Imaging. 2009;2(2):176-82.

3. Torres FSM, Carolina Medaglia, Vianna FFG, Miguel. Medida da espessura das camadas íntima e média das artérias carótidas para avaliação do risco cardiovascular. Rev Bras Hipertens. 2007;14(3):167-71.

4. Roelke LH, Rodrigues SL, Lotufo PA, Mill JG. Correlation between the intima-media thickness of the proximal and distal common carotids. Arq Bras Cardiol. 2013;101(3):211-6.

5. Gurovich AN, Braith RW. Pulse wave analysis and pulse wave velocity techniques: are they ready for the clinic? Hypertens Res. 2011;34(2):166-9.

6. Sabovic M, Safar ME, Blacher J. Is there any additional prognostic value of central blood pressure wave forms beyond peripheral blood pressure? Curr Pharm Des. 2009;15(3):254-66.

7. Brandão AB, Amodeo C, Alcantara C, Barbosa E, Nobre F, et al. I Luso Brazilian Positioning Paper on Central Arterial Pressure. Arq Bras Cardiol. 2017; 108(2):100-8. and interpretation of the data: Melo MA, Vitorino P, Jardim PC, Jardim T, Souza WKSS. Statistical analysis: Melo MA, Vitorino P, Souza WKSS. Writing of the manuscript: Melo MA, Vitorino P, Arantes AC, Rezende J, Jardim T, Souza WKSS. Critical revision of the manuscript for intellectual content: Melo MA, Vitorino P, Jardim PC, Jardim T, Souza WKSS.

\section{Potential Conflict of Interest}

No potential conflict of interest relevant to this article was reported.

\section{Sources of Funding}

There were no external funding sources for this study.

\section{Study Association}

This article is part of the thesis of master submitted by Milena de Andrade Melo, from Universidade Federal de Goiás.

\section{Ethics approval and consent to participate}

This study was approved by the Ethics Committee of the HC-UFG under the protocol number 000985/2016. All the procedures in this study were in accordance with the 1975 Helsinki Declaration, updated in 2013. Informed consent was obtained from all participants included in the study.
8. Hametner B, Wassertheurer S, Kropf J, Mayer C, Eber B, Weber T. Oscillometric estimation of aortic pulse wave velocity: comparison with intra-aortic catheter measurements. Blood Press Monit. 2013;18(3):173-6.

9. Kaess BM, Rong J, Larson MG, Hamburg NM, Vita JA, Levy D, et al. Aortic stiffness, blood pressure progression, and incident hypertension. JAMA. 2012;308(9):875-81.

10. Ding FH, Fan WX, Zhang RY, Zhang Q, Wang JG. Validation of the Noninvasive Assessment of Central Blood Pressure by the SphygmoCor and Omron Devices Against the Invasive Catheter Measurement. Am J Hypertens. 2011;24(12):1306-11.

11. Vlachopoulos C, Xaplanteris P, Aboyans V, Brodmann M, Cifkova R, Cosentino $\mathrm{F}$, et al. The role of vascular biomarkers for primary and secondary prevention. A position paper from the European Society of Cardiology Working Group on peripheral circulation: Endorsed by the Association for Research into Arterial Structure and Physiology (ARTERY) Society. Atherosclerosis. 2015;241(2):507-32.

12. Malachias MVB, Souza WKSB, Plavnik FL, Rodrigues CIS, Brandão AA, Neves MFT, et al. 7a Diretriz Brasileira de Hipertensão Arterial. Arq Bras Cardiol 2016; 107(3Supl.3):1-83

13. Bonilla PI, Sánchez EM, Peralta JL, Oquendo MI. Validación de dos sistemas de automedida de presión arterial, modelos OMRON HEM-705 CP y OMRON M1 (HEM 422C2-E). Aten Primaria 2002;30(1):22-8. 
14. Williams B, Mancia G, Spiering W, Agabiti Rosei E, Azizi M, Burnier M, et al. 2018 ESC/ESH Guidelines for the management of arterial hypertension. Eur Heart J. 2018;39(33):3021-104.

15. Smith SC, Jr., Benjamin EJ, Bonow RO, Braun LT, Creager MA, Franklin $\mathrm{BA}$, et al. AHA/ACCF secondary prevention and risk reduction therapy for patients with coronary and other atherosclerotic vascular disease: 2011 update: a guideline from the American Heart Association and American College of Cardiology Foundation endorsed by the World Heart Federation and the Preventive Cardiovascular Nurses Association. J Am Coll Cardiol. 2011;58(23):2432-46.

16. Bruno RM, Bianchini E, Faita F, Taddei S, Ghiadoni L. Intima media thickness, pulse wave velocity, and flow mediated dilation. Cardiovascular ultrasound. 2014;12(1):34.

17. Lorenz MW, Sitzer M, Markus HS, Bots ML, Rosvall M. Prediction of clinical cardiovascular events with carotid intima-media thickness: A systematic review and meta-analysis-Response.[Letter]. Circulation. 2007;116(9):E318.

18. Kablak-Ziembicka A, Tracz W, Przewlocki T, Pieniazek P, Sokolowski A, Konieczynska M. Association of increased carotid intimamedia thickness with the extent of coronary artery disease. Heart. 2004;90(11):1286-90.

19. Nagai K, Shibata S, Akishita M, Sudoh N, Obara T, Toba K, et al. Efficacy of combined use of three non-invasive atherosclerosis tests to predict vascular events in the elderly; carotid intima-media thickness, flow-mediated dilation of brachial artery and pulse wave velocity. Atherosclerosis. 2013;231(2):365-70.

20. Taniwaki H, Kawagishi T, Emoto M, Shoji T, Kanda H, Maekawa $\mathrm{K}$, et al. Correlation between the intima-media thickness of the carotid artery and aortic pulse-wave velocity in patients with type 2 diabetes. Vessel wall properties in type 2 diabetes. Diabetes Care. 1999;22(11):1851-7.
21. Gil TY, Sung CY, Shim SS, Hong YM. Intima-media thickness and pulse wave velocity in hypertensive adolescents. J Korean Med Sci. 2008;23(1):35-40.

22. Kobayashi K, Akishita M, Yu W, Hashimoto M, Ohni M, Toba K. Interrelationship between non-invasive measurements of atherosclerosis: flow-mediated dilation of brachial artery, carotid intima-media thickness and pulse wave velocity. Atherosclerosis. 2004;173(1):13-8.

23. Munakata M, Ito N, Nunokawa T, Yoshinaga K. Utility of automated brachial ankle pulse wave velocity measurements in hypertensive patients. Am J Hypertens. 2003;16(8):653-7.

24. Jatoi NA, Mahmud A, Bennett K, Feely J. Assessment of arterial stiffness in hypertension: comparison of oscillometric (Arteriograph), piezoelectronic (Complior) and tonometric (SphygmoCor) techniques. J Hypertens. 2009;27(11):2186-91.

25. Reshetnik A, Gohlisch C, Tolle M, Zidek W, Van Der Giet M. Oscillometric assessment of arterial stiffness in everyday clinical practice. Hypertens Res. 2017;40(2):140-5.

26. Zureik M, Temmar M, Adamopoulos C, Bureau J-M, Courbon D, Thomas F, et al. Carotid plaques, but not common carotid intima-media thickness, are independently associated with aortic stiffness. J Hypertens. 2002;20(1):85-93.

27. Naqvi TZ, Lee MS. Carotid intima-media thickness and plaque in cardiovascular risk assessment. JACC Cardiovasc Imaging. 2014;7(10):1025-38.

28. Zureik M, Bureau JM, Temmar M, Adamopoulos C, Courbon D, Bean K, et al. Echogenic carotid plaques are associated with aortic arterial stiffness in subjects with subclinical carotid atherosclerosis. Hypertension. 2003;41(3):519-27.

29. Prati P, Tosetto A, Casaroli M, Bignamini A, Canciani L, Bornstein N, et al Carotid plaque morphology improves stroke risk prediction: usefulness of a new ultrasonographic score. Cerebrovasc Dis. 2011;31(3):300-4. 